\title{
Research on the E-commerce Development Strategies of Small and Medium-sized Enterprises in Quanzhou Based on Content Analysis
}

\author{
Taking Goldeer Corporation as An Example*
}

\author{
Yiping Hong \\ College of Economy \& Management \\ Liming Vocational University \\ Quanzhou, Fujian, China 362000
}

\begin{abstract}
Under the background of the rapid development of e-commerce in the current era, whether small and medium-sized enterprises can effectively develop e-commerce is the key to the survival and development of enterprises. In this study, taking Quanzhou's local enterprise, Goldeer Corporation as an example, we have collected 31,421 effective customer reviews from its Tmall flagship store. The total number of words is approximately 710,000 . The content analysis method was used to study the samples. The results showed that: customers concern the actual effect of products the most; the speed of express delivery the second; packaging and branding the third; the price the last. Basing on the results, we have made some suggestions for the e-commerce development of small and medium-sized enterprises: 1. The utility of products should be put in the first place in e-commerce marketing; 2 . Provide more convenient and efficient online shopping experience; 3 . Pay attention to the consistency of product packaging and promotion, to enhance corporate branding; 4. Focus on products' cost performance and never fall into the whirlpool of price competition.
\end{abstract}

Keywords-content analysis; small and medium-sized enterprises(SMEs); e-commerce; strategies

\section{INTRODUCTION}

Since it was proposed in Chinese first "the Eleventh FiveYear Plan of E-commerce Development"that e-commerce is a network-based new economic activity in June 2007, ecommerce as a core application of economic informatization has become the country's effective means to enhance economic competitiveness and gain global resource allocation. It has been widely recognized that by developing e-commerce we can save costs, expand marketing channels, optimize resource allocation and enhance corporate core competitiveness.

In recent years, in the southeast region of China, especially in Quanzhou, south of Fujian which has prosperous privatelyowned economy, small and medium-sized enterprises have become more aware of the importance of developing ecommerce. However, e-commerce has not been actually

*Fund Project: Research Project of Young Teachers in Education Department of Fujian Province (No. JAS171073). popularized among enterprises. And the enterprises which have already started e-commerce have failed to make effective use of various resources. To this end, the research on the obstacles to the implementation of e-commerce for small and medium-sized enterprises in Quanzhou is currently of great significance. We take Goldeer Corporation, a well-known privately owned enterprise in Fujian Province as an example, collect the customers' reviews in the official flagship store in Tmall Mall, use ROST software for analysis, discuss the problems existing in e-commerce development, and put forward strategies to solve the problems.

\section{RESEARCH STATUS}

In foreign countries, researchers often study factors that influence the implementation of e-commerce by small and medium-sized enterprises from the following aspects. The first one is using technology adoption model represented by Tarafda, Chircu, Kauffman, et al.[1].The second is from the perspective of the impact on business performance of the implementation of e-commerce[2] represented by Tea, Wei, Chatterjee, et al.. These two studies mostly focused on technology and theory. Although the method, theory and results have got a breakthrough, they do not have universal significance because the studies are based on the special development period. Pateli believes that e-commerce is a recent phenomenon. The basis for its establishment is the widespread use of computers and networks. So far, there is no comprehensive theoretical system and implementation method [3].

From the search results of CNKI data, as early as in 1998, some domestic scholars began to pay attention to e-commerce of small and medium-sized enterprises. Gao Wei and Qiao Kaihong first proposed that e-commerce is an effective way for small and medium-sized enterprises to exist and develop[4], after which many researches on small and medium-sized enterprises' e-commerce has appeared. Especially in the years from 2005 to 2014 , the researches about this topic were the most, the amount reached the peak in 2008, as shown in Fig. 1. However, most of the studies explore the development strategy and model of small and medium-sized enterprises e-commerce 
from the perspective of national strategies and policies, for example, Tang Min and Gao Yongfa discussed the development of SMEs E-commerce from the development status of e-commerce in China[5]; There are also scholars who explored the construction of SMEs e-commerce platform and technical protection from the perspective of computer science and technical means, such as Liu Xuejing's research topic: Alternatives of SME accounting networked software in Ecommerce environment [6]; In addition, some scholars have discussed this topic from the perspectives of marketing [7], finance [8], internet technology [9], finance and tax [10], and investment [11].However, there are not many researches that analyzed from the perspective of customer evaluation. Therefore, this paper is intended to make an attempt from this perspective in order to make a useful supplement to the research of this topic and provide SMEs with useful references on the development of e-commerce, and open up new research perspectives for other researchers.

\section{RESEARCH DESIGN}

\section{A. Research Methods and Tools}

Content Analysis Method is a research method that quantitatively, systematically and objectively analyzes the content of a given text. The essence of it is transform the information contained in the text from qualitative to quantitative, making it easy to count and analyze. That is to select data that can reflect the features, characteristics, attributes, etc. of the text content, and can be measured and calculated from the text. By this way the analysis results is relatively objective. This study uses content analysis method to analyze the customers' reviews to get a result of customers' perceptions of products, logistics, and corporate brands.

This research selects the Rost content analysis system invented by Professor Shenyang in Wuhan University as an analytical tool. This analysis tool has been widely used in China, having a series of text analysis functions such as microblogging analysis, chat analysis, full-network analysis, web site analysis, browsing analysis, word segmentation, word frequency statistics, English word frequency statistics, data flow analysis, cluster analysis, etc., and the system is stable.

\section{B. Data Collection and Processing}

We began to collect customer reviews from Goldeer's official flagship store in Tmall Mall in March 2007. From the opening of the flagship store to January 25, 2018,we have collected all customer reviews of 21 products sold by Goldeer in Tmall Mall. We have excluded comments without written descriptions (including reviews that only contain stars, expressions, symbols, etc.), merchants' responses to customer reviews and insubstantial comments. Merge repeated reviews from the same customer after one shopping behavior. After sorting and statistics, we got 31,421 effective comments, and the total number of words is approximately 710,000 . We have collated and reviewed all comments, then removed punctuation marks, paragraph symbols, and English abbreviations in the text. Finally, the text is saved as "raw data.txt" waiting to be extracted participles and high-frequency feature words.

\section{High-Frequency Feature Word Extraction}

First of all, before extracting high-frequency feature words, we need to establish a customized vocabulary table and merge the words with the same meaning to provide convenience to the statistics of word frequency in next process. For example, compile the words "once again", "second time", "next time", etc. uniformly as "once again", compile "brand", "old brand", "Goldeer", etc. as "brand". Second, import the "raw data.txt" file into ROST, use the word segmentation function to segment the words, and automatically generate the "raw data-word segmentation.txt" file. Third, the "raw data - word segmentation.txt" file is once again imported into ROST. At the same time, the pre-established customized vocabulary table is imported together to extract high-frequency words and automatically generate "raw data - word segmentation - high frequency words. txt", open the file, after checking we can obtain high-frequency feature words related to the research topic, as shown in the following "Table I" 
TABLE I. Customer Evaluation High Frequency Word STATISTICAL TABle

\begin{tabular}{|c|c|c|c|c|c|c|c|c|c|c|c|}
\hline $\begin{array}{c}\text { Seque } \\
\text { nce }\end{array}$ & $\begin{array}{c}\text { High } \\
\text { Frequency } \\
\text { Word } \\
\end{array}$ & $\begin{array}{c}\text { Frequenc } \\
\mathbf{y}\end{array}$ & $\begin{array}{c}\text { Seque } \\
\text { nce }\end{array}$ & $\begin{array}{c}\text { High } \\
\text { Frequency } \\
\text { Word } \\
\end{array}$ & Frequency & $\begin{array}{c}\text { Seq } \\
\text { uen } \\
\text { ce }\end{array}$ & $\begin{array}{c}\text { High } \\
\text { Frequency } \\
\text { Word } \\
\end{array}$ & Frequency & $\begin{array}{c}\text { Seq } \\
\text { uenc } \\
\mathrm{e}\end{array}$ & $\begin{array}{c}\text { High } \\
\text { Frequency } \\
\text { Word } \\
\end{array}$ & $\begin{array}{c}\text { Frequ } \\
\text { ency }\end{array}$ \\
\hline 1 & Effect & 5627 & 26 & Use & 763 & 51 & Friend & 260 & 76 & Obviously & 160 \\
\hline 2 & Taste & 4753 & 27 & Service & 705 & 52 & Practical & 250 & 77 & Heat & 158 \\
\hline 3 & Mosquito & 3412 & 28 & $\begin{array}{l}\text { Cost- } \\
\text { effective }\end{array}$ & 660 & 53 & Tasteless & 250 & 78 & Talent & 154 \\
\hline 4 & $\begin{array}{l}\text { Mosquito } \\
\text { coils }\end{array}$ & 2976 & 29 & Seller & 648 & 54 & Using & 250 & 79 & Postal & 154 \\
\hline 5 & Praise & 2973 & 30 & Smell & 619 & 55 & As always & 242 & 80 & Combustion & 153 \\
\hline 6 & Receive & 2041 & 31 & Worth it & 608 & 56 & Last year & 242 & 81 & Faint & 153 \\
\hline 7 & Did not use & 1758 & 32 & Speed & 596 & 57 & Rubbish & 236 & 82 & Good & 153 \\
\hline 8 & Logistics & 1616 & 33 & Brand & 577 & 58 & The second & 232 & 83 & Disappointed & 147 \\
\hline 9 & Buy & 1375 & 34 & Effective & 534 & 59 & Trust & 223 & 84 & Valuable & 146 \\
\hline 10 & Commodity & 1363 & 35 & Attitude & 534 & 60 & $\begin{array}{l}\text { Mosquito } \\
\text { control }\end{array}$ & 223 & 85 & Imagine & 143 \\
\hline 11 & Satisfaction & 1330 & 36 & Sandalwood & 493 & 61 & $\begin{array}{l}\text { Look } \\
\text { forward to }\end{array}$ & 221 & 86 & Try & 143 \\
\hline 12 & Cheap & 1325 & 37 & Mouse & 491 & 62 & Five points & 216 & 87 & Counterfeit & 143 \\
\hline 13 & Package & 1252 & 38 & Authentic & 483 & 63 & Shopping & 214 & 88 & Suggest & 143 \\
\hline 14 & Quality & 1229 & 39 & Time & 465 & 64 & Truly & 213 & 89 & Comfortable & 143 \\
\hline 15 & Fragrance & 1135 & 40 & This time & 403 & 65 & Five stars & 204 & 90 & Rest assured & 143 \\
\hline 16 & Affordable & 1082 & 41 & Convenient & 366 & 66 & Try out & 192 & 91 & $\begin{array}{ll}\text { Value } & \text { for } \\
\text { money } & \end{array}$ & 141 \\
\hline 17 & $\begin{array}{l}\text { Express } \\
\text { delivery }\end{array}$ & 1051 & 42 & Inexpensive & 338 & 67 & Not very & 188 & 92 & Peculiar smell & 139 \\
\hline 18 & $\begin{array}{l}\text { The second } \\
\text { time }\end{array}$ & 1033 & 43 & Goldeer & 331 & 68 & Useful & 183 & 93 & Third & 135 \\
\hline 19 & Cockroach & 1031 & 44 & The first time & 323 & 69 & Box & 179 & 94 & Price & 121 \\
\hline 20 & Quickly & 925 & 45 & Pungent & 317 & 70 & Entity & 178 & 95 & Honest & 121 \\
\hline 21 & Ship & 872 & 46 & Baby & 309 & 71 & It works & 177 & 96 & Bathroom & 120 \\
\hline 22 & Evaluation & 821 & 47 & A coil of & 302 & 72 & Completely & 175 & 97 & Suitable & 120 \\
\hline 23 & Supermarket & 782 & 48 & Add & 265 & 73 & Visit & 167 & 98 & Last time & 118 \\
\hline 24 & Next time & 771 & 49 & Come back & 264 & 74 & Old brand & 165 & 99 & Sleep & 115 \\
\hline 25 & At night & 770 & 50 & Offer & 264 & 75 & Repurchase & 162 & 100 & Picture & 114 \\
\hline
\end{tabular}

\section{Construction of Content Analysis Categories}

Through the high-frequency feature word statistical table and the semantic analysis chart ("Fig. 1"), classify the highfrequency feature words, and construct the customer evaluation content analysis category list, as shown in the following "Table II".
TABLE II. CUSTOMER EVAlUATION CONTENT ANALYSIS CATEGory LIST

\begin{tabular}{|c|c|c|c|}
\hline $\begin{array}{c}\text { Main } \\
\text { Category }\end{array}$ & Subcategory & $\begin{array}{c}\text { Main } \\
\text { Category }\end{array}$ & Subcategory \\
\hline \multirow{6}{*}{$\begin{array}{l}\text { Product } \\
\text { properties }\end{array}$} & Smell & \multirow{5}{*}{ Logistics } & Speed \\
\hline & Effect & & Customer service \\
\hline & Genuine or not & & Logistics packaging \\
\hline & $\begin{array}{l}\text { Product } \\
\text { packaging }\end{array}$ & & Ship \\
\hline & Brand & & Including mailing \\
\hline & Price & \multirow{5}{*}{ Evaluation } & Star rating \\
\hline \multirow{2}{*}{$\begin{array}{l}\text { Customer } \\
\text { service }\end{array}$} & Speed & & Satisfied \\
\hline & Attitude & & Buy again \\
\hline \multirow{2}{*}{$\begin{array}{l}\text { Online } \\
\text { purchase } \\
\text { reasons }\end{array}$} & Convenient & & $\begin{array}{l}\text { Recommend others } \\
\text { to buy }\end{array}$ \\
\hline & Affordable & & Trust \\
\hline
\end{tabular}




\section{E. Emotion Analysis of Customer Evaluation}

Import the "raw data-word segmentation. txt" file into ROST, and analyze the overall emotion tendency of customer evaluation using the emotion analysis function. The statistical results are shown in "Table III ".

TABLE III. CUSTOMER EVALUATION EMOTION ANALysis Result Statistics

\begin{tabular}{|c|c|c|c|c|c|c|c|c|c|c|}
\hline Emotion & \multicolumn{3}{|c|}{ Positive Emotion } & \multicolumn{3}{|c|}{ Neutral Emotion } & \multicolumn{3}{|c|}{ Negative Emotion } & Note \\
\hline \multirow{3}{*}{$\begin{array}{l}\text { Analysis } \\
\text { Results }\end{array}$} & General & $\begin{array}{c}\text { Medium } \\
\text { level }\end{array}$ & $\begin{array}{l}\text { High } \\
\text { level }\end{array}$ & General & $\begin{array}{c}\text { Medium } \\
\text { level }\end{array}$ & $\begin{array}{l}\text { High } \\
\text { level }\end{array}$ & General & $\begin{array}{l}\text { Mediu } \\
\text { m level }\end{array}$ & $\begin{array}{l}\text { High } \\
\text { level }\end{array}$ & \multirow{3}{*}{$\begin{array}{l}\text { Neutral emotion } \\
\text { without } \\
\text { distinguishing } \\
\text { intensity }\end{array}$} \\
\hline & $54.34 \%$ & $11.58 \%$ & $\begin{array}{l}4.18 \\
\%\end{array}$ & - & - & - & $4.18 \%$ & $0.32 \%$ & 0 & \\
\hline & \multicolumn{3}{|l|}{$70.10 \%$} & \multicolumn{3}{|l|}{$25.40 \%$} & \multicolumn{3}{|l|}{$4.50 \%$} & \\
\hline
\end{tabular}

\section{RESULTS AND DISCUSSION}

After social and semantic network analysis is performed on the "raw data-word segmentation.txt" file, we can obtain the
Trust

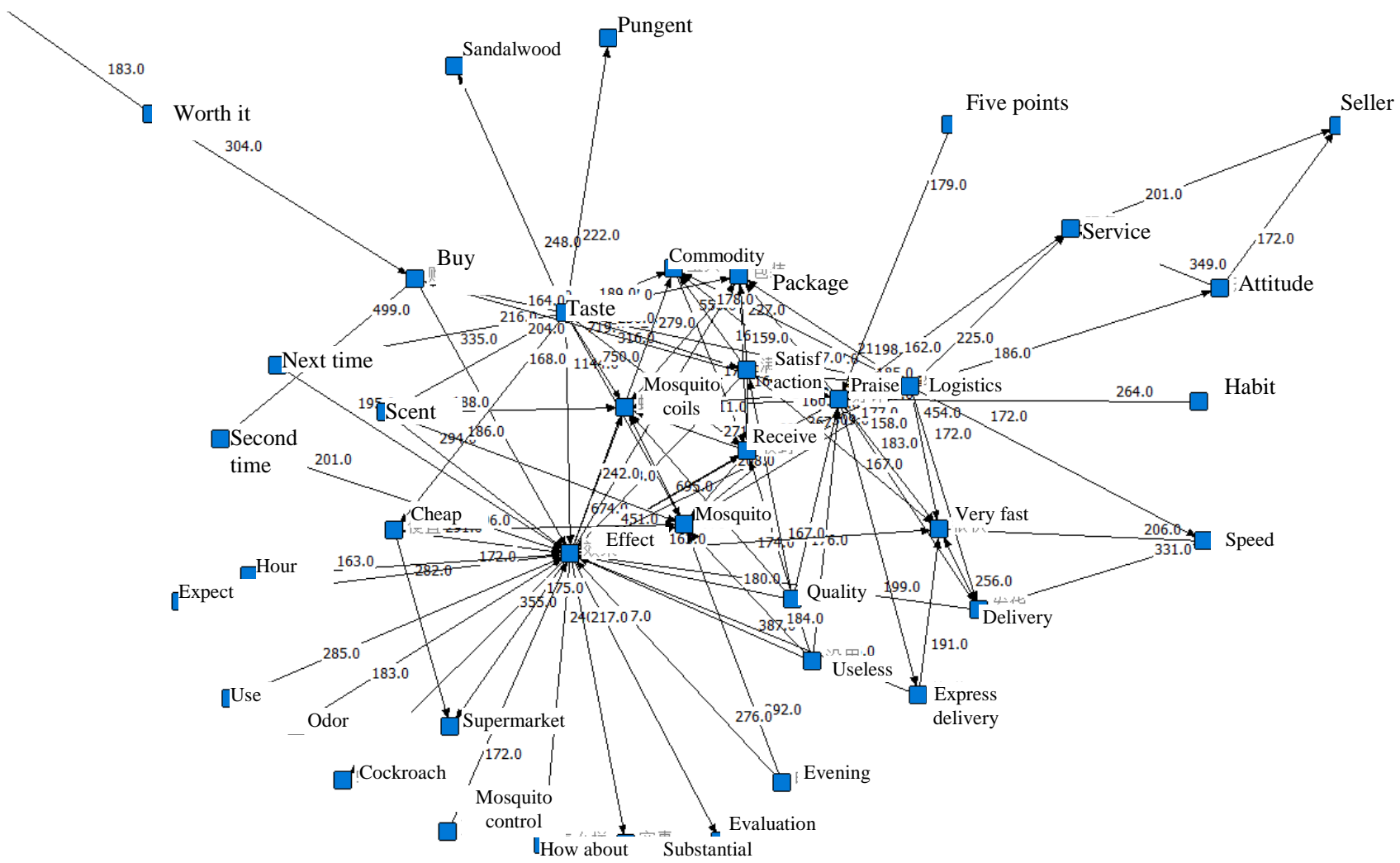

Fig. 1. Social and semantic network analysis diagram of customer evaluation of Goldeer's products.

As can be seen from the figure, "effects", "mosquitoes", "mosquito coils", "taste", "satisfaction", "logistics", "packaging", "praise", etc. theses words are related to other words the most, and appear most frequently in customers' reviews. They are called the center node of the graph. The closer other words get to these words, the more closely they relate to them. From the comparison of the high-frequency feature vocabularies with the analysis diagram constructed in this study, the high degree of agreement between them shows that the results are reliable. "raw data-word segmentation-line feature word-co-word matrix.xls" file. Using the Netdraw, a visualized graphic can be generated. It is shown in "Fig. 1". 
essentially the same as the word "effect". In addition, from the high-frequency feature words "logistics" (1616), "packaging" (1252), and "affordable" (1082), it can be found that the customers' also concern about delivery and logistics speed, product and express packaging, the product cost performance, etc., which are basically the same as the previous analysis category.

\section{B. Customers' Concerns}

From the high-frequency feature words ("Table I") and the semantic network analysis diagram ("Fig. 1"), it can be found that customers concern about the effect the most, so we construct a semantic analysis map with the "effect" as a key word, as shown in "Fig. 2" below. It can be found that in addition to product-related words, "effect" is closely related to "satisfaction", "praise", "repurchase", etc. Therefore, it can be inferred that the effect is the direct power to promote customers to buy again, and that online shopping customers are rational.

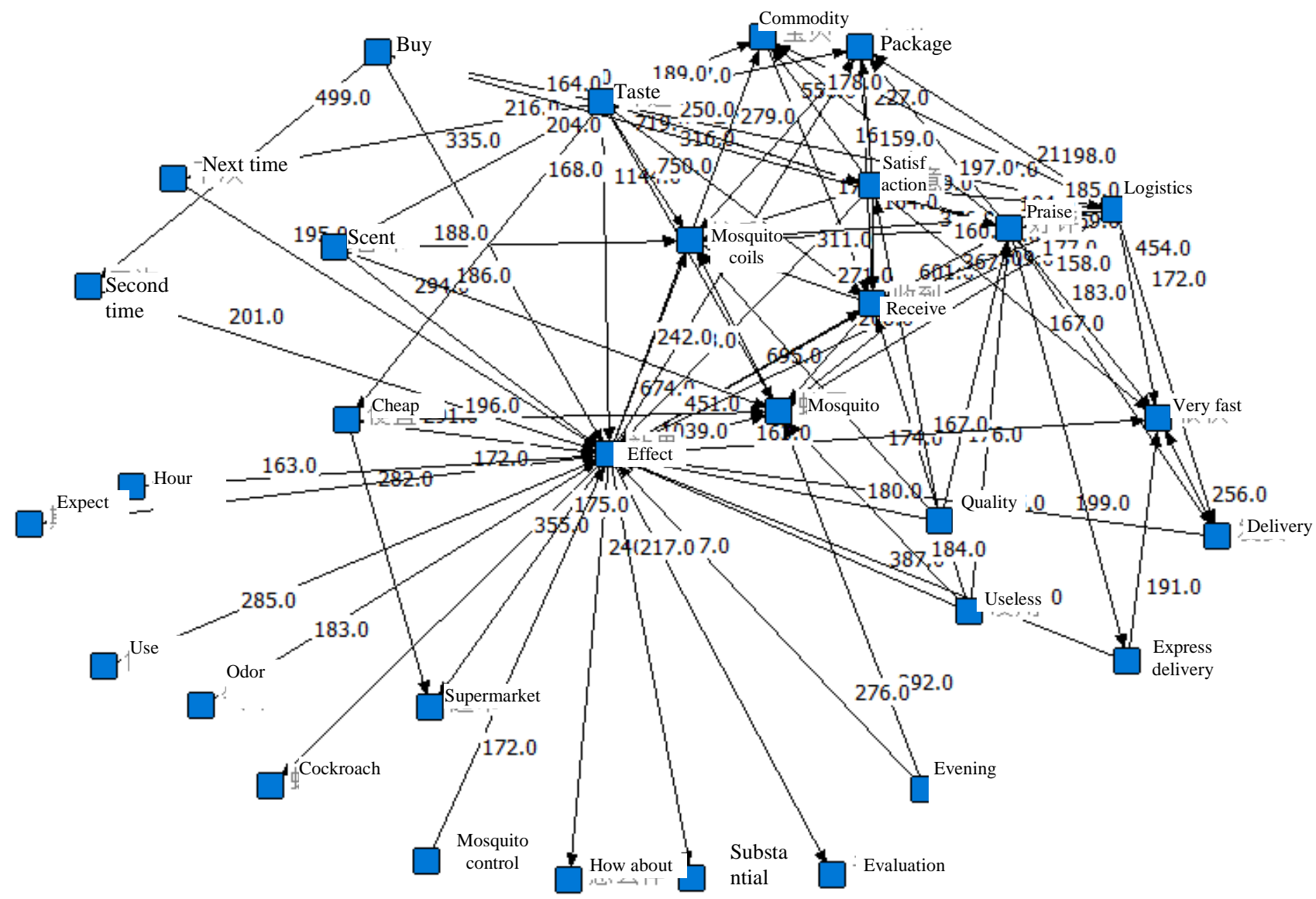

Fig. 2. Social Network and Semantic Analysis of Customers' Evaluation of Product Effect.

\section{Customers' Evaluation about Logistics}

The semantic network analysis diagram is constructed with the keyword of logistics, as shown in Fig. 3 below. From the figure, we can find that words closely related to logistics include: baby (i.e., product), quickly, receive, praise, satisfaction, ship, speed, service, packaging, attitude, etc. This shows that customers are more concerned about the express delivery company selected by the store, and the shipping speed of the store is also one of the customers' focuses. Combining with the high frequency vocabulary, customers are more satisfied with the service of express delivery, the praises are more. This coincides with the condition that there are currently a number of express delivery companies in our country, the competition is fierce and companies have regarded service as their core competitiveness. 


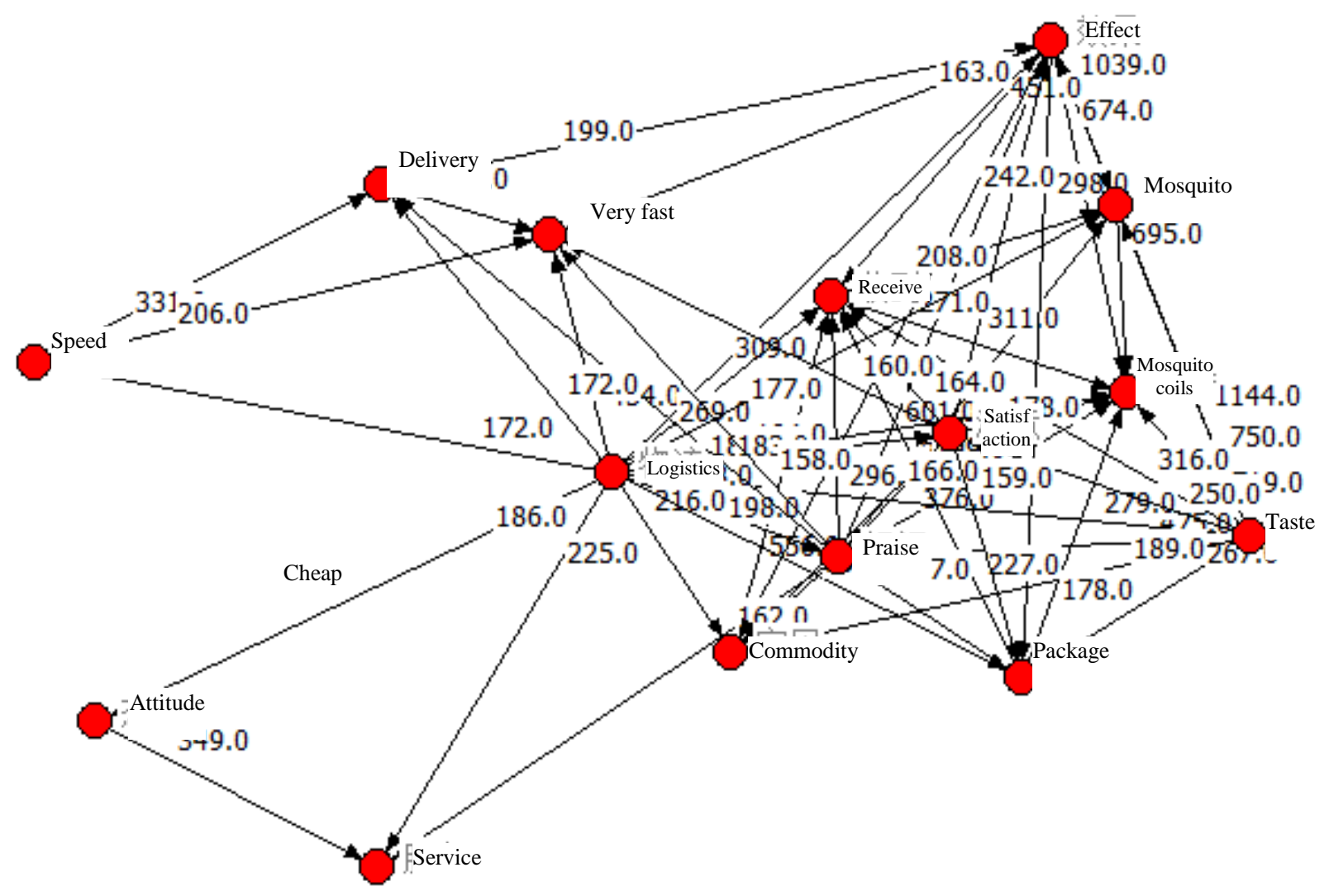

Fig. 3. Semantic Network Analysis Diagram of Customers' Evaluation to Logistics.

\section{Customer Satisfaction Evaluation}

Construct the semantic network diagram with the keyword of "satisfaction", as shown in Fig. 4. From the figure, we can see that customers' satisfaction with online shopping is mainly related to the product itself, logistics, packaging, effects, and quality. So the effect and quality of the product are the focus of customers, which coincides with the fact that customers concern that there are too many counterfeits in online shopping malls. However, from the content analysis table ("Table II"), the main reason for customers to choose online shopping is that it is convenient and affordable, but the semantic network analysis chart does not reflect the word "affordable", which can be inferred that customers really feel convenient through online shopping but don't feel affordable. Customers feel that the products' cost performance is not good enough, and online stores are not more favorable than physical stores.

\section{E. Customer Evaluation Emotion Analysis}

From the results of customer emotion analysis shown in Table III, the overall evaluation of Goldeer's Tmall flagship store is positive. From the analysis of positive emotions, there is only $4.18 \%$ of highly positive emotions, $11.58 \%$ of mediumlevel positive emotions. It can be seen that there is still a lot of room for customers to promote positive emotions. From the standpoint of negative emotions, the proportion of moderate negative emotions is $0.32 \%$, and the proportion of highly negative emotions is 0 . Almost all negative emotions are of a general degree. If the company can find the crux, truly understand the customers' complaints, it will be relatively easy to eliminate negative emotions of customers.

\section{CONCLUSIONS AND SUGGESTIONS}

\section{A. Conclusion}

From the data analysis of the sample, the customers' evaluation to Goldeer Tmall flagship store is relatively high. From the high-frequency feature words, semantic analysis and network analysis results, customers mostly concern about the actual effect of the product, the speed of logistics the second, product packaging and branding the third, the price of the product the last. From this, it can be seen that, first, online shopping customers are relatively rational, shopping online is to meet their actual needs. Second, customers really care about the logistics, which is also a test for stores and express delivery companies, especially during shopping festivals and statutory holidays. Third, product packaging is another major factor affecting customers' selection. However, packaging costs are one of the factors that companies have to consider. Companies need to think further about how to balance it. Fourth, costeffectiveness is not the most important factor in all factors. This may be due to the improvement of people's living standards. They are willing to pay more for really good products. This reminds companies that to improve product 
quality and provide satisfactory products for customers is the right direction.

\section{B. Suggestions}

(1) In view of the rational purchase behavior of online shopping customers, SMEs should really understand the needs of customers and provide them with high-quality products. Whether the company sells products on its own platform or on a third-party platform, only high-quality products can impress customers, enhance corporate brand and attract customers to buy again. After all, all other potential customers can see the customers' evaluation. This also explains why customers trust official flagship stores much more than non-official stores.

(2) Convenience and promptness are the main factors that attract customers to shop online. SMEs need to provide such services continuously. There are great psychological differences between online shopping and real store purchasing. Customers can immediately get the goods after paying in offline stores. If there are problems they can be solved at the scene. The customer has a high degree of trust for the store and a strong sense of obtainment. On the other hand, online shopping is not the case. The customer's psychological needs can not be met after paying the money until the customer receives the product. And the product quality is uncertain. Although the money can only be paid to the store after the customer affirms the product is received.

(3) Enterprises must improve the external packaging of their products. Online shops and physical stores bring different visual perceptions to customers, the goods in physical stores are real, but online stores can process photos by tools. It is deceptive. Most introductions of online goods is vivid. If the customer receives a product that is inconsistent with the online description, it constitutes a fraudulent act for the customer. Therefore, it is recommended that companies should pay attention to the matching of actual product packaging and online introduction, and at the same time improve the actual packaging to attract customers, which can also enhance the corporate brand.

4) The inertial idea "price is the most important factor in attracting consumers" of SMEs should be changed. As people's living standards being improved, customers may not care about the price of products, but more concern that whether enterprises can provide effective products. So SMEs need to change the behavior of price publicity, and should not be caught in the whirlpool of price competition.

\section{Research Insufficiency and Follow-up Study Suggestions}

1) Research insufficiency: We use customer online shopping evaluation as the sample, use ROST for content analysis, although it has been objective as far as possible, there is a gap between the research results and actual situation. Because many online shops encourage customers to express favorable comments on the website with paying rewards to them, some evaluations cannot truly reflect customers' feelings.

2) Follow-up study suggestions: In order to make the research results closer to the actual situation, other similar companies can be chosen to repeat the research process. We can compare the results to verify whether the research results are valid.

If having the condition, merchants are recommended to set up questionnaires and distribute them to online shopping customers for quantitative analysis to make the research results more accurate, more instructive, and of more reference value.

\section{REFERENCES}

[1] Dantzig G B, Ramser J H. The truck dispatching problem[J]. Management science, 1959, 6(1),pp.80-91.

[2] Blanton Jr J L, Wainwright R L. Multiple vehicle routing with time and capacity constraints using genetic algorithms[C]//Proceedings of the 5 th International Conference on Genetic Algorithms. Morgan Kaufmann Publishers Inc. 1993,pp.452-459.

[3] Pateli A G, Giaglis G M. A research framework for analysing eBusiness models[J]. European journal of information systems, 2004, 13(4),pp.302-314.

[4] Gao Wei, Qiao Kaihong. E-commerce: An Effective Tool for the Subsistence and Development of SMEs[J]. Decision \& Information. 1998(12),pp.14-15.

[5] Tang Min, Gao Yongfa. Discussion on the Development of Electronic Commerce in Chinese Small and Medium-sized Enterprises[J]. Exploration of Economic Issues. 2005(11),pp.116-119.

[6] Liu Xuejing. The Choice of SME Accounting Networking Software in E-Commerce Environment[J]. Jiangsu Business Theory. 2007(10),pp.143-145.

[7] Wu Weie. Research on E-Commerce Market Strategy for Small and Medium-sized Enterprises Coping with Financial Crisis[J]. Productivity Research, 2009(14),pp.151-152.

[8] Zhao Yue, Tan Zhibo. E-Commerce, Bank Credit, and SME Financing: A Theoretical Model Based on Information Economics [J]. Economic Research. 2012(07),pp.99-112.

[9] Gao Hong, Liu Kehai. Discussion on the Mode of E-commerce Websites for Small and Medium-sized Enterprises[J]. Computer System Application. 2000(08),pp.7-9.

[10] You Chun. Research on the optimization of SME tax system in the era of 3G mobile e-commerce[J]. Tax \& Economy. 2010(02),pp.74-78.

[11] Zhao Chunyan. Innovation and development countermeasures of the ecommerce loan model for private small and medium-sized enterprises in the context of credit crunch: based on the comparison of development models in the United States and South Korea [J]. Special Economic Zone, 2011(10),pp.216-217. 